\title{
Introducing High School Students to Engineering Disciplines: Activities and Assessment
}

\section{Dr. Nicolas Ali Libre, Missouri University of Science and Technology}

Nicolas Ali Libre, $\mathrm{PhD}$, is an assistant teaching professor of Civil Engineering at Missouri University of Science and Technology. He received his BS (2001), MS (2003) and PhD (2009) in civil engineering with emphasis in structural engineering, from University of Tehran, Iran. His research interests and experiences are in the field of computational mechanics, cement-based composite materials as well as innovative teaching techniques. Dr. Libre is the manager of Materials Testing lab at Missouri S\&T, teaches mechanics of materials and develops digital educational resources for the engineering students. He had the opportunity of leading several scientific and industrial research projects and mentoring graduate and undergraduate students. Over the span of his career, Dr. Libre authored and co-authored 3 chapter books, 17 peer-reviewed journal articles and over 60 conference papers. He has advised and co-advised 8 graduate students and mentored over 30 undergraduate students. He has collaborated with scholars from several countries, including Iran, China, Slovenia, Canada, and the US. He also served as a reviewer for 6 journals and a committee member of 5 conferences. He is the recipient of the University of Missouri President Award for Innovative Teaching (2018), the Teaching with Technology Award in the Focus on Teaching and technology conference (2018), Joseph H Senne Jr. Academy of Civil Engineering Faculty Teaching and Service Achievement Award (2017) and the Excellence in Teaching Award from the National Society of Leadership and Success (2016).

\section{Dr. Stuart Werner Baur, Missouri University of Science and Technology}

A registered architect and civil engineering doctorate, joined the faculty of the University of Missouri Rolla in 2002. Dr. Baur spent seven years in the architectural/engineering firms of Arquitectonica, The Nichols Partnership, and Bermello Ajamil and Partners in South Florida. Baur's notable projects included the American Embassy in Lima, Peru, the Banque of Luxembourg, the Sawgrass Mills Mega Mall, and the American Airlines Concourse A expansion at the Miami International Airport.

In 2002 Baur became part of the university's solar house project and since then has continued working with the 2005 solar house and on the 2007 solar house project as their main faculty advisor. He continues to work with the solar house team as a faculty advisor for the 2009, 2013, 2015 and 2017 solar decathlon as well. Some of his related endeavors include the development of a solar village which also serves as a student housing and research facility that educates the public about renewable energy technology including various methods techniques that involve energy efficient lighting design and daylight integration.

As an educator Baur has participated several session on various lighting design techniques including the Philips' Lighting Application Center. He has also co-authored a book entitled, Civil Engineering and Architecture to be used as a textbook for all Project Lead the Way CEA curriculum. The book highlights some of the drivers to energy-efficient design including the use different types of lighting systems including daylighting.

\section{Dr. Mark Fitch, Missouri University of Science and Technology}

Mark Fitch is an Associate Professor and Assistant Chair for Environmental Engineering in the Department of Civil, Architectural, and Environmental Engineering at Missouri University of Science and Technology.

Prof. William Eric Showalter P.E., Missouri University of Science and Technology 


\title{
Introduce High School Students to Engineering Disciplines: Activities and Assessment
}

\author{
Nicolas A. Libre ${ }^{1}$, Stuart W. Baur ${ }^{1}$, Mark Fitch ${ }^{1}$, W. Eric Showalter ${ }^{1}$ \\ Department of Civil, Architectural and Environmental Engineering, Missouri University of \\ Science and Technology
}

\begin{abstract}
Pre-college summer camps are part of the successful recruiting efforts at Missouri S\&T; The undergraduate enrollment at Missouri S\&T has increased 23\% in the past 10 years. This paper documents and describes the educational summer camp program developed for high school students. The overarching, broader impact goal of the summer camp is to introduce students to various engineering disciplines and help them to make a better decision on choosing a career or discipline within engineering. Several activities are designed to achieve the goal. The summer camp attracts about 300 to 400 high school students across the country every summer. This research study focuses on the hands-on activities offered by Missouri S\&T, College of Engineering and Computer Science programs. Activity details in the Civil Engineering, Architectural Engineering and Environmental Engineering programs are described in this paper and the results are discussed. Students showed success in implementing the engineering principles into basic engineering problems through a problem-based learning activity. Students enjoyed the activities and showed improved learning after the hands-on program. A survey is also conducted at the end of the activity to understand the students' perception of the conducted activities and to enhance the program based on students feedback. Overall the summer camp was very positive for both the participants and their mentors.
\end{abstract}

Key words: Intro to Engineering, Problem based learning, summer camp, High school students

\section{Introduction}

Making a decision to be an engineer and choosing an engineering discipline are challenging for senior high school students who have limited knowledge about various engineering disciplines. Such a decision is even more challenging for first-generation college students or minority students due to the lack of knowledge on higher education, lack of the information they need to choose the right discipline and school, limited access to resources to ask questions and even not knowing the right questions to ask along the decision making process [1]. There have been several programs to introduce high school students to engineering and science. Some programs target high school teachers and some other programs directly involve high school students [2]-[5]. The Jackling Introduction to Engineering Camp (or just Intro Camp) is a 5-day program offered by Missouri University of Science and Technology (Missouri S\&T) to introduce high school students to various engineering disciplines. Missouri S\&T is a technological 4-year 
university where over $80 \%$ of the undergraduate students are majoring in engineering. Total on-campus enrollment has increased from 5155 students in 2009 to 6324 students in 2019 with a peak of 6801 students in 2017 (see Figure 1). The successful undergraduate recruitment is partially attributed to the precollege summer camps; the oldest and largest of which is called Jackling Introduction to Engineering.

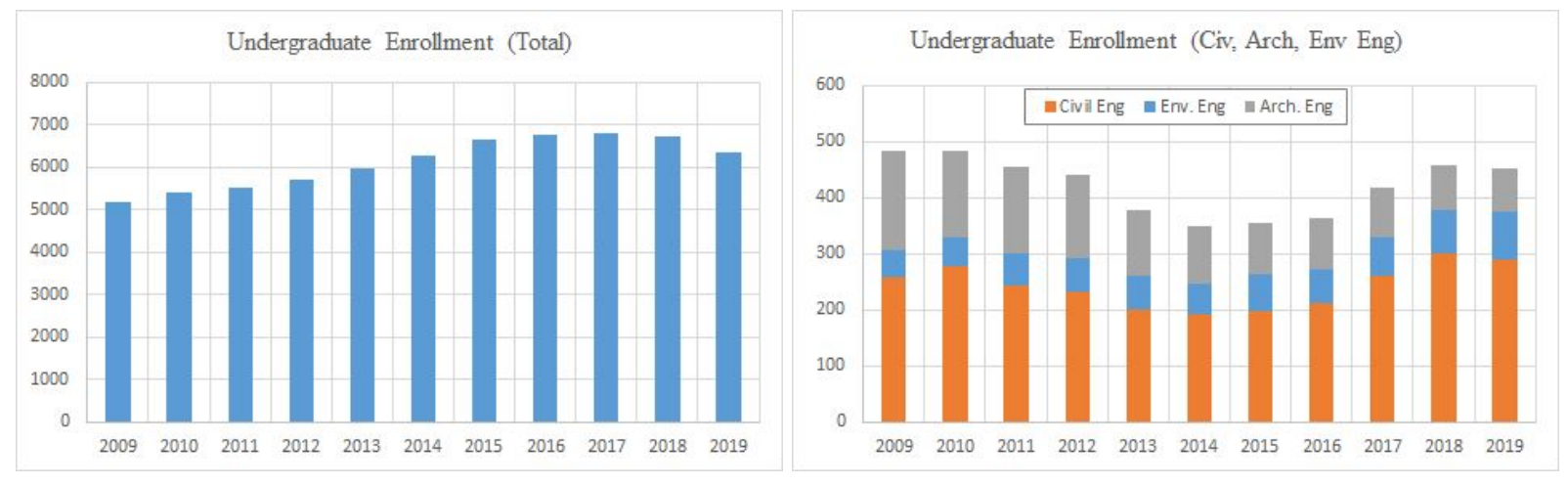

Figure 1. Undergraduate enrollment in the past 10 years, left) all majors, right) Civil, Architectural and Environmental Engineering

\section{History of the Intro summer camp, goals and targeted students}

The Jackling Institute was founded in 1973 to introduce students to the less common engineering disciplines of metallurgical engineering, ceramic engineering, nuclear engineering, mining engineering, geological engineering, and ceramic engineering as well as the non-engineering degree program in geology and geophysics. A similar summer camp called Intro to Engineering was established in early 1990 for the mainstream engineering disciplines such as mechanical, civil, electrical, and chemical engineering [6]. The two separate summer camps were combined in 2004 and the combined program is known as Jackling Introduction to Engineering. The Jackling Intro camp is designed to introduce high school students to various aspects of engineering by employing presentations, hands-on exercises and active learning activities. The Camp that occurs at three different times during the summer is geared to high school juniors and seniors in order to help them identify the kind of engineering that is best for them. The Intro Camp was established with the following goals: (1) increasing students' knowledge of various engineering disciplines, (2) enhancing students understanding on how math and science relate to the field of engineering through hands-on activities, (3) introducing the educational and research opportunities at Missouri S\&T, and (4) preparing high school students for making a thought-out decision on choosing a career or disciplines they want to pursue.

Several activities are designed to achieve these goals. During the summer camp, visiting students live in residence halls for five nights, walk daily on campus, attend classes and work in labs. An overview of each discipline is given on the first day of camp. Participants then have the opportunity to select five departments to explore in more depth. Visiting each department 
includes providing detailed presentation of the discipline followed by a tour on lab facilities guided by faculty and grad or undergrad students. Students also gain experiences during the department visits by doing a hands on activity and testing their understanding and skills in friendly student competition. All students also participate in a team design competition and recreational activities.

The camp program is financially self-sufficient and has successfully attracted a diverse group of participants. On average, about 300 to 500 students attend the Intro camp every summer, with the majority of students coming from all over the state of Missouri as well as from surrounding states. Demographic analysis of participants in 2019 sessions show $77.6 \%$ of students are from Missouri, 7.5\% from Illinois, 3.4\% from Kansas, 3.1\% from Texas and the rest came from Arkansas, California, Colorado, Iowa, Massachusetts, Michigan, Minnesota, Nebraska, Oklahoma, Tennessee, and Wisconsin; $22 \%$ of students were female and $78 \%$ were male. Figure 2 , summarizes the demographic information of participants in the 2019 sessions. The number of students varied each year but the same trend was observed in the previous years.
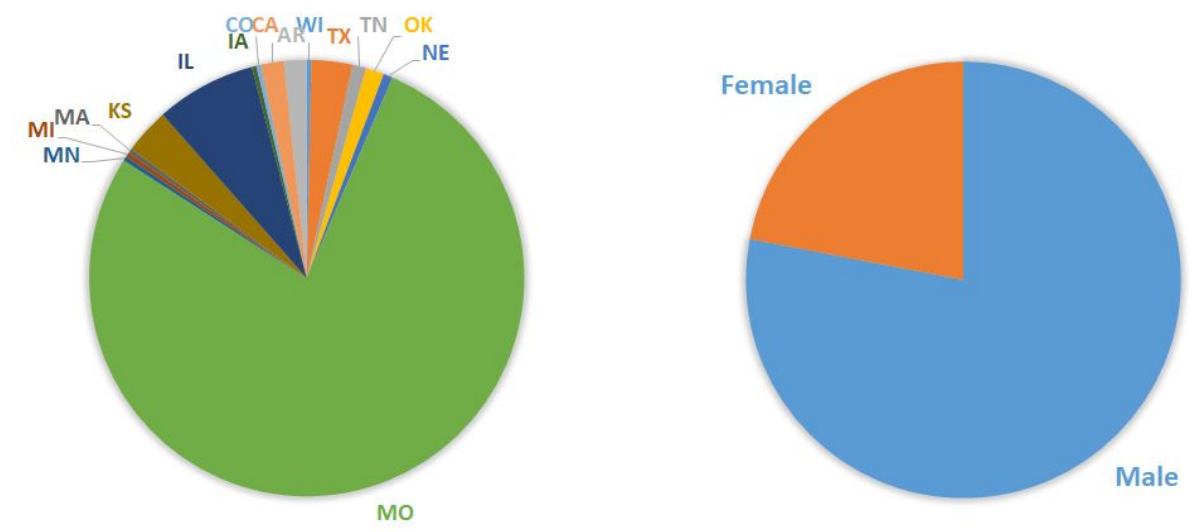

Figure 2. Demographic information of participating students in 2019 program

\section{Hands-on activities in Civil and Architectural Engineering:}

At the camp, students will learn how math and science relate to the field of engineering. By seeing first-hand what engineers actually do, campers can better decide on a career or discipline they want to pursue. Whether a student is interested in clean energy, cars and motorcycles, explosives, or building bridges or towers, the camp will educate them through hands-on activities, computer laboratory visits and practical demonstrations. The civil and architectural engineering program is no exception to this exercise. Both programs offer a tour through some of the various research/laboratory facilities and provide similar demonstrations in statics and mechanics of materials. What the students saw in the labs is further reinforced in the classroom by conducting a project based learning (PBL) exercise. 
Architectural Engineering: The architectural engineering program offers a PBL exercise known as, "The Great Popsicle Tower Challenge." This exercise tests several key factors and provides insight as to how an engineer must learn to work together with a partner or partners to find a solution that is both viable and aesthetically pleasing. This is particularly true for architectural engineering as they work with architects and other related building professionals in the industry. In terms of skill, the tower has several key factors. They include strength to weight ratio, height to weight ratio and overall aesthetics. The challenge lies in the understanding as to what type of structural system provides the greatest amount of capacity with the least amount of materials. The limitations are simple. In approximately 1-1/2 hour in teams of 2 to 3 members in a group design a tower that is a minimum of 12 inches tall using a maximum of 150 Jumbo Size Popsicle Sticks. The top of the tower is to provide a flat surface to support steel plates weighing 25 pounds each with a maximum total maximum weight of 150 pounds. With each stick having a maximum of 6 inches in length the group must design the tower with a minimum of two Popsicle sticks standing on each end. The students may cut the sticks. The assembly of sticks employs the use of a hot glue gun and refillable glue sticks for ease yet rapid production. Figure 3, shows some of the creative results and testing of towers from this past summer. The criteria for a successful design are three main categories. The strength to weight ratio, the height to weight ratio and the overall aesthetics. The aesthetics is also important because architectural engineers will be working with other disciplines that will be critical of a buildings overall appearance. The maximum points for each of the three categories equates to 20,10 and 20 respectively.
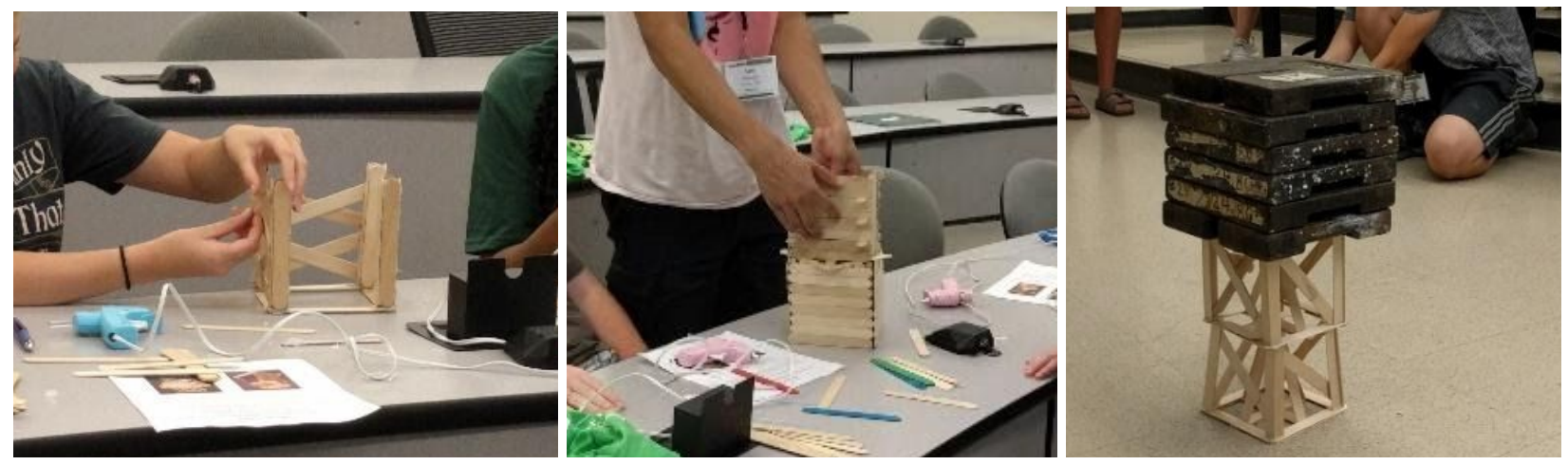

Figure 3. Images of 2019 Summer Popsicle Tower Challenge

Civil Engineering: The Civil Engineering hands on activity is designed to introduce students to structural components used in the buildings and infrastructures. After a brief introduction to truss structures, students were asked to design, build and test a bridge that spans $18 \mathrm{in}$. long, at least 2 $1 / 2$ in. wide and is subjected to a concentrated force at the mid-span. Students are split into different teams, each team is provided with a pack of K'Nex that includes plastic rods, stems and connectors. The snap-fit pieces stick together securely and carry a limited amount of load in tension, compression and flexure. Students can attach the plastic parts together to create a variety of bridges. All connections are snap-fit that eliminates the use of glue or other connecting 
materials; also allows for testing and reconnecting to find out the weak point in the design and fine tune it before the final test. The challenge lies in the understanding as how the forces are transferred from the mid-span to the side supports, what is the best span structural geometry to carry the load and how to optimize the connections to achieve the maximum capacity of the bridge with the least amount of materials. On average, students spent 1.5-2 hours designing and building the bridge.

The bridges were tested for three-point bending with a concentrated load at the middle of the beam up to failure. A typical test setup is shown in Figure 4. The structural efficiency is measured using equation (1)

$$
S E=\frac{F_{\max }}{w}
$$

where $F_{\max }$ is the maximum load before failure and $\mathrm{w}$ is the weight of the bridge.

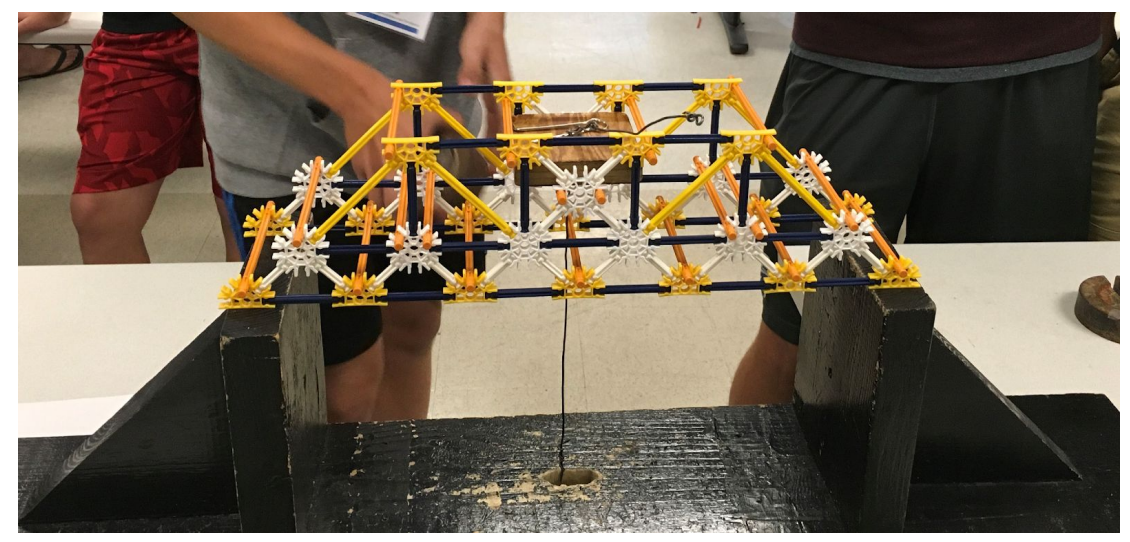

Figure 4- Test setup for bridge loading test

\section{Observations:}

During the hands on activity, students had the opportunity to practice an engineering problem on a smaller scale. One of the main challenges for high school students who are playing the role of novice engineer, is to come up with an optimum design given the limited time also discussing their design with the other team members. It was observed that the initial discussion stage is typically very short (less than 5 minutes) and students quickly start assembling different parts and testing their bridge. The first bridge is typically made in about 30 min after starting the activity. The third stage is the optimization process where the teams test their bridge to optimize their design by adding or replacing some parts.

Team collaboration: It was observed that most of the teams kept the initial design and changes were limited to adding some components to increase the capacity or replacing the weak connectors at the failure points. The number of radical changes in the design was very limited even in cases where students had some extra time to redesign the bridge. Some teams started 
with different ideas and chose the best based on the performance in the loading test. Even though the teamwork seemed to be demanding, many teams collaborated effectively in various stages. Many students interacted with the peers enthusiastically and contributed in designing and making the bridge; there were very limited students who didn't contribute or made their own bridge as individuals.

The most fun part of the activity for many students was the final test where each team had one chance to test their bridge. The friendly environment of competition had a positive impact on students' performance. During the past three years (nine camp sessions) there was just one incident where a team showed displeasure against the other team during the final test that required the advisor intervention. Many teams got inspired by observing other design approaches that helped them to fine tune their design. Figure 5, show some of the creative bridge designs made by students during the 2019 camp sessions.
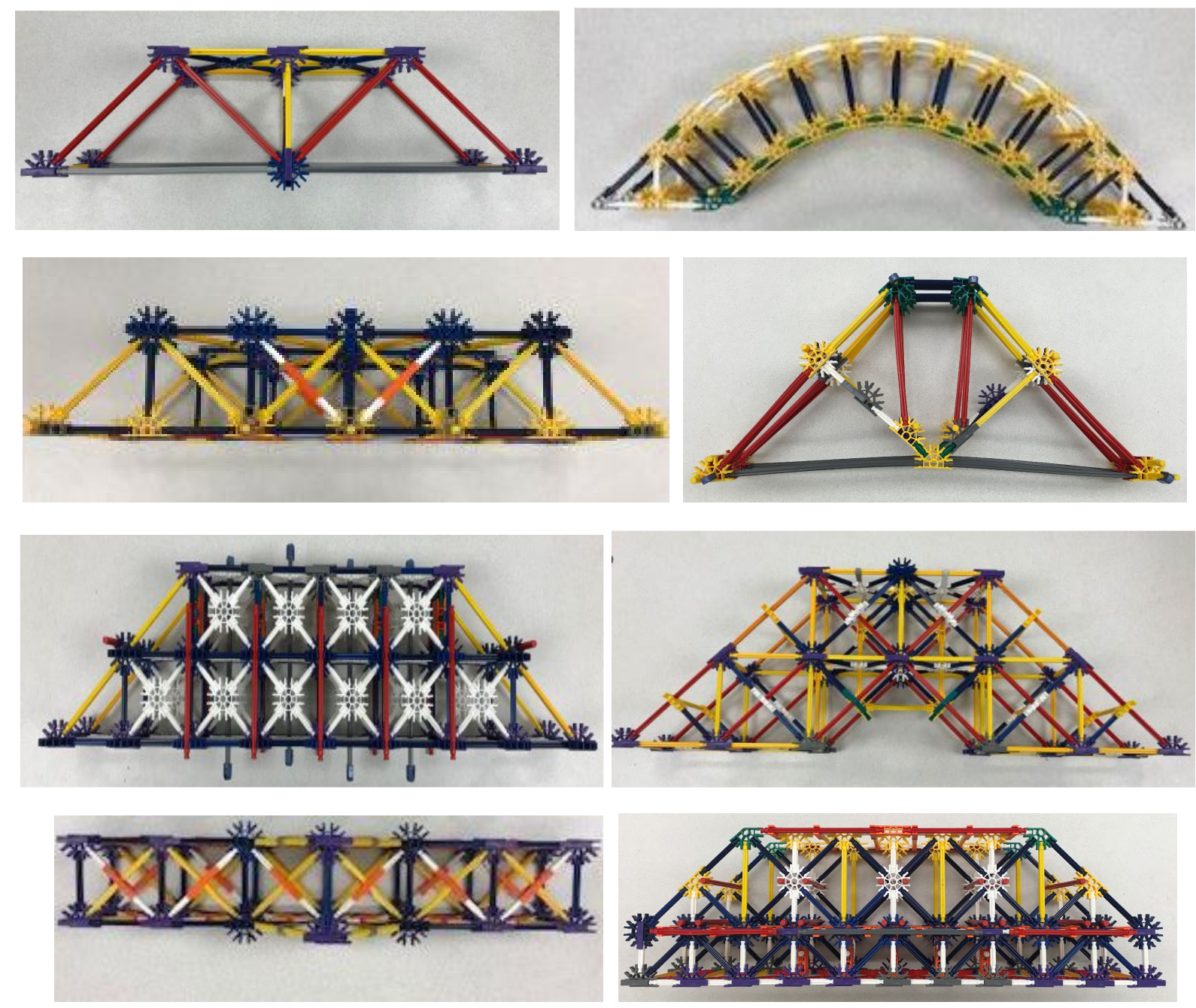

Figure 5- Some bridges made by students 
Team performance: The performance of 49 teams in 6 summer camp sessions were recorded to provide more insight on member's interaction, team functioning, and students learning. The overall average structural efficiency of all teams is $\mathrm{SE}=62.2$ with the standard deviation of 27.3. The minimum and maximum values were 23.3 and 133.0. Figure 6 shows the histogram distribution of all results with the bin size of 10 . The results distribution is not a regular normal distribution; but it is more like a bimodal histogram with two peaks. The first peak bin with the most often SE values is the bin 30-40 and the second peak is 70-80.

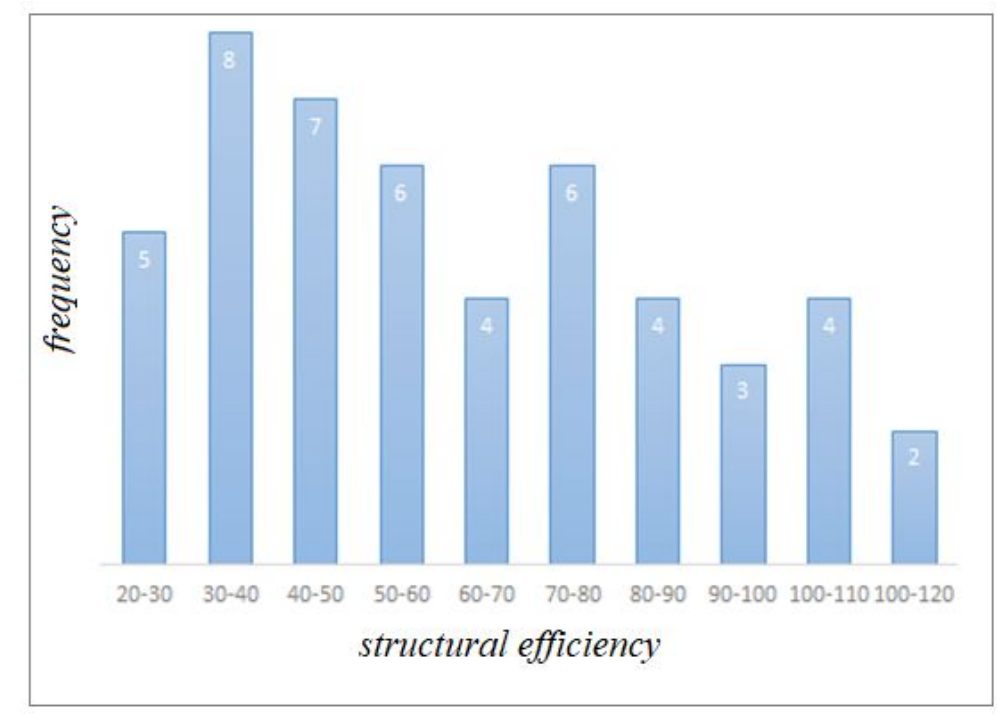

Figure 6- Histogram distribution of structural efficiency of all teams ( $n=49)$

Another interesting finding is the performance of teams with different numbers of members. Figure 7 shows the boxplot of structural efficiency of the bridges made by teams with different numbers of members. Based on the statistical analysis, the optimum number of members in a team is 4 that showed the highest median of $\mathrm{SE}=70$. The median of $\mathrm{SE}$ for the teams with 5 members has dropped to $\mathrm{SE}=64.1$. Regarding the limited time and the given activity, an explanation for the drop is the lack of leadership that prevents the efficient utilization of the fifth members in the team. The teams with 3 members showed the lowest performance with the median of $\mathrm{SE}=43.1$. An interesting finding is the team with only 2 members. Even though the median value is $\mathrm{SE}=55.8$, this category showed the highest average among all teams with $\mathrm{SE}=69.1$. This is attributed to the excellent performance of a few teams with the $\mathrm{SE}>100$. The results confirm that a small team with quality members could over perform other teams with more number of students (higher available resources) at least for small tasks with a limited time. 


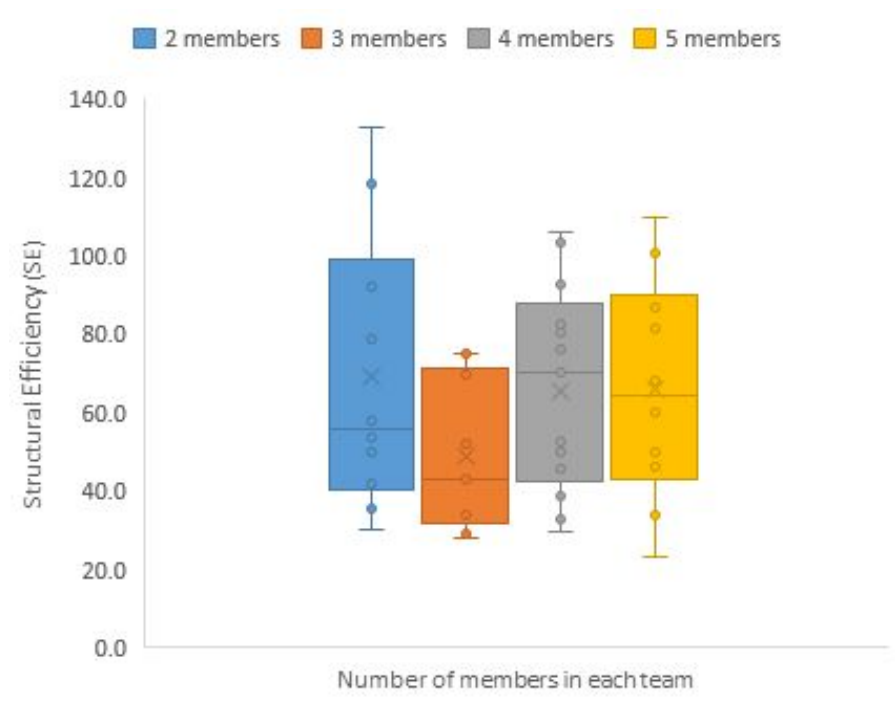

Figure 7- Performance of teams with different number of members

\section{Student's feedback and future work:}

After the exercise, we asked the students what are some of the lessons learned from this challenge. The responses focused on the importance of team collaboration, understanding basic engineering principles in terms of both materials and their assemblies as a whole, and the appreciation of the profession.

Overall the Intro summer camp was very positive for both the participants and their mentors. Many students appreciated the hands-on activities and mentioned they enjoyed working in a team to solve a problem and being able to make and test structural components.

Recommendations for future years were largely operations and included the suggestions to spend more time for the lab. Here are some representative feedbacks:

"I liked that I could see what was happening right away. I liked that I could manipulate a material to do what I needed it to do."

"I liked how we had to work as a team in order to complete a common goal."

"It involved trial and error until we came about the bridge we wanted."

"The great professors and students taught be the importance of civil engineering"

"I enjoyed creating the bridge and making something with ideas that we all contributed and combined to create something cool." 


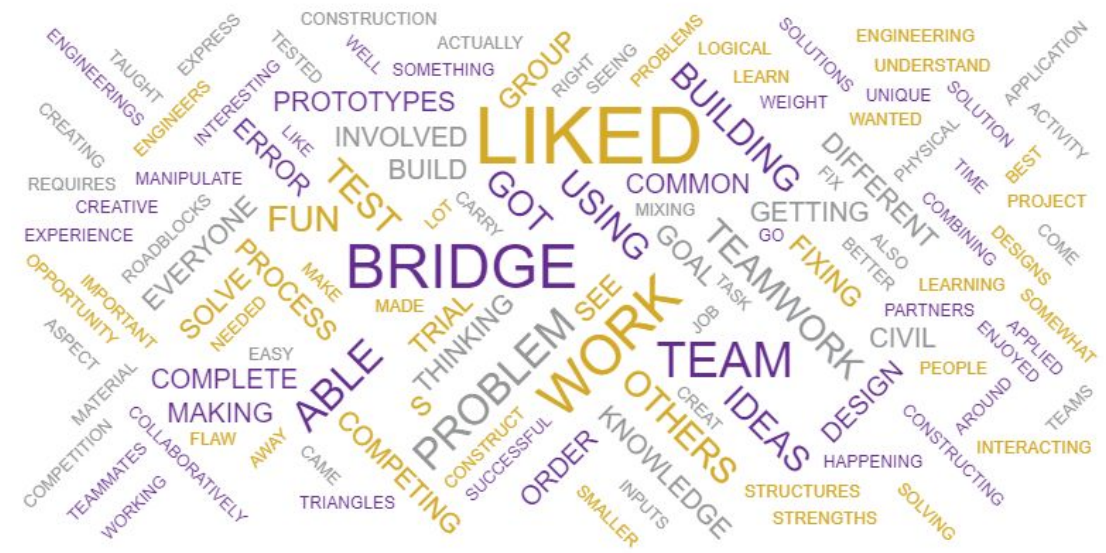

Figure 8- Word cloud of students' response to what they liked about the hands on activity

The word cloud of student's response to the question "what they liked about the hands on activity" as demonstrated in Figure 8, shows that that students favorite aspects of the hands on activity are designing and prototyping bridges, team working and competing with other teams. Another survey was conducted among 18 currently enrolled sophomore and Junior students in different engineering disciplines who have attended the summer camp when they were high school students. Students were asked to rate if the camp helped them in learning about various engineering disciplines. The average rating was 4.17 on the scale of 1 to 5. Also, their response to the statement "I felt more prepared to choose my engineering major after attending the summer camp program." was 4.00 on the same scale. Following are some responses on what they liked and did not like about the summer camp.

"I liked the opportunity to visit the different departments and speak to actual students or professors in that engineering discipline. I also appreciated that the activities in each department were geared to help specifically high school aged students learn and were at an appropriate level for their understanding. Additionally most of the activities were very hands on. The only thing I would change about the camp is maybe add a design team element or something to show what you can do with engineering in a real world setting. I don't think I remember there being something like this."

"I liked everything about it, I got a bunch of exposure to campus and what the different disciplines of engineering were like."

"I was forced to go by my parents but really enjoyed going. Don't have anything to complain about."

"I liked the people gated where we stayed TJ was horrible. There was a positive in being there for a week though as I learned that there is no way I could ever live in a place like that." 
"I liked the tours and the designing of the final project I didn't like the room setups and the food"

"I liked how each department that was visited had an activity to get a feel of what the major is. I wish there had been a more in depth discussion about what that major entails like what you would be doing after graduation and maybe even talk about course work"

All surveyed students ended up majoring in one of the engineering disciplines that they have visited during the summer camp indicating a successful introduction of students to various engineering programs.

\section{References}

[1] Moody, J. (2019). "What to Know as a First-Generation College Student," USNews.com. Accessed July 15, 2019. https://www.usnews.com/education/best-colleges/articles/2019-05-14/what-you-should-kno w-as-a-first-generation-college-student

[2] Cardella, M.E., Knight,D.B., Lee, W.C., Reid,K.W., Hynes,M.M., G.D. Collins, Beauchamp, Dandridge, T., Colquitt, D., (2019). "Promoting the Participation of Elementary School African Americans, Hispanics, and Girls in STEM by Expanding Summer Engineering Experiences" ASEE Annu. Conf. Expo. Conf. Proc.,

[3] Drummond, M., Cardella,M.E., Sydlik, M., Everett, M., (2019). "Developing Summer Research Programs at an NSF ERC: Activities, Assessment, and Adaptation", ASEE Annu. Conf. Expo. Conf. Proc.,

[4] Campbell, S.W., Bhethanabotla, V.R., Thomas,S.W., (2019) "RET in Functional Materials and Manufacturing", ASEE Annu. Conf. Expo. Conf. Proc.,

[5] Evans, G.N., Crippen, K.J., Simmons, C.S., (2019). "The Mentoring Network of K-5 Educators and Engineering Researchers in an RET", ASEE Annu. Conf. Expo. Conf. Proc.,

[6] Elmore, C.E., Flori, E.F., (2008), “The University of Missouri-Rolla's Jackling Intro to Engineering Summer Camp", World Environmental and Water Resources Congress, ASCE, Ahupua'a, HI 